\title{
Dynamic imaging of Ostwald ripening in copper oxide nanoparticles by atomic resolution transmission Electron microscope
}

\author{
Na Yeon Kim®
}

\begin{abstract}
Structural evolution of copper oxide nanoparticles is examined, especially with respect to Ostwald ripening under electron beam irradiation. Dissolution of the smaller particles into the larger one was clearly observed at the atomic scale using advanced transmission electron microscope.
\end{abstract}

Keywords: Ostwald ripening, Atomic diffusion, Transmission Electron microscopy, Copper oxide nanoparticle, Atomic resolution image

\section{Description}

Ostwald ripening is a well-known crystal growth phenomenon, arising from unbalanced atomic diffusion from smaller nanoparticles with higher surface energy to bigger one (Voorhees 1985; Kuo et al. 2013; Ouyang et al. 2013). Transmission electron microscopy (TEM) is adequate to demonstrate the phenomenon associated with atomic diffusion and migration using state-of-theart techniques (Bell et al. 2010). Herein, we show in-situ structural evolution in copper oxide nanoparticles $\left(\mathrm{Cu}_{\mathrm{x}} \mathrm{O}\right.$ $\mathrm{NPs}$ ), especially in terms of crystallization and Ostwald ripening under electron beam irradiation in TEM. The amorphous copper oxide, widespread residues on CVD graphene surfaces (Lupina et al. 2015), shows crystallization from non-crystalline to hexagonal-like lattice structures with random orientation during electron-beam irradiation (Fig. 1 a). When the two crystallized blue and green $\mathrm{Cu}_{\mathrm{x}} \mathrm{O}$ NPs become close to each other, Ostwald ripening occurs by atomic diffusion from the blue $\mathrm{Cu}_{\mathrm{x}} \mathrm{O} \mathrm{NP}$ to the green one. In particular, it appears that the smaller blue $\mathrm{Cu}_{\mathrm{x}} \mathrm{O} \mathrm{NP}$ with $2 \mathrm{~nm}$ in diameter rotated around 23 degree to diffuse into the larger green one just after $0.2 \mathrm{~s}$ acquisition time (Fig. 1b, c). On the other hand, the green $\mathrm{Cu}_{\mathrm{x}} \mathrm{O}$ NP just rotated a fraction of degree. Misorientation in the growing

Correspondence: nayeon418@gmail.com

Center for Multidimensional Carbon Materials (CMCM), Institute for Basic Science (IBS), Ulsan 44919, Republic of Korea
$\mathrm{Cu}_{\mathrm{x}} \mathrm{O}$ NP involves double reflections and blur in digital diffractograms (yellow insets of Fig. $1 \mathrm{c}$ and d) and elongation on the outermost lattices (Fig. $1 \mathrm{~d}$ ). After prolonged e-beam irradiation of approximately $10 \mathrm{~s}$, it appears that the $\mathrm{Cu}_{\mathrm{x}} \mathrm{O}$ $\mathrm{NP}$ was transformed into the well-crystallized structure of hexagonal lattices in absence of defects like twin boundaries (Fig. 1 e).

This image provides direct evidence of Ostwald ripening regarding the phenomenon that the smaller particles have higher solubility owing to higher surface energy by showing atomic dissolution and rotation of $\mathrm{Cu}_{\mathrm{x}} \mathrm{O}$ NPs under atomic scale investigation.

\section{Acknowledgements}

Not applicable.

\section{Authors' contributions}

NYK performed the experiment and wrote the manuscript. The author read and approved the final manuscript.

\section{Funding}

This work was supported by the Institute for Basic Science (IBS-R019-D1).

Availability of data and materials

Not applicable. "Please contact author for data requests."

\section{Competing interests}

The authors declare that they have no competing interests.

\section{Springer Open}


(A)
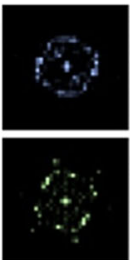

(B)
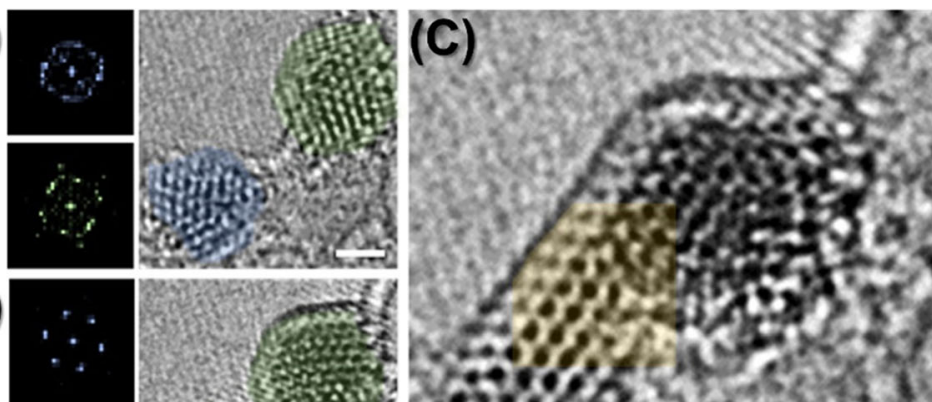

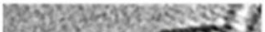
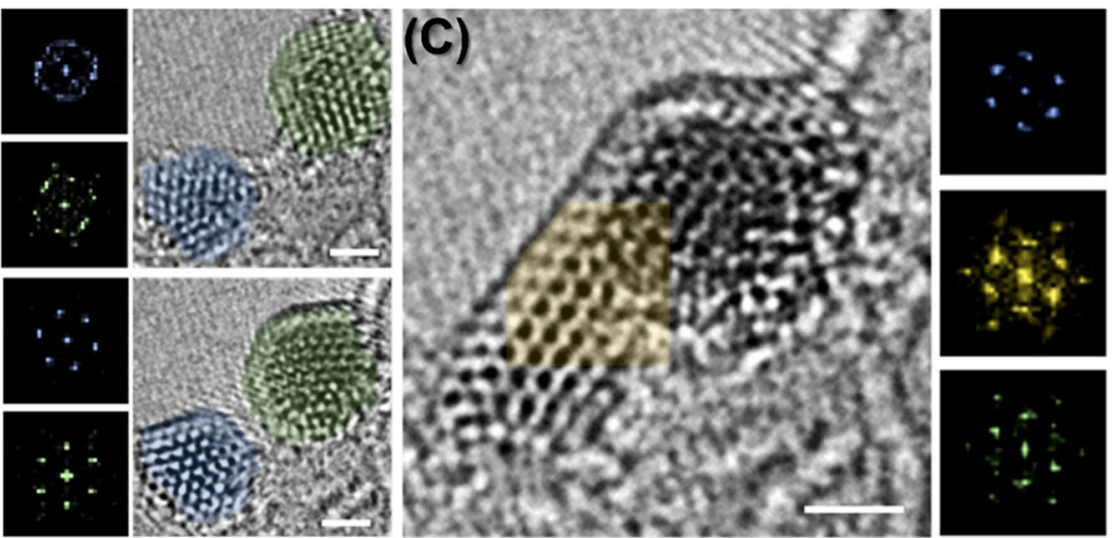

(D)

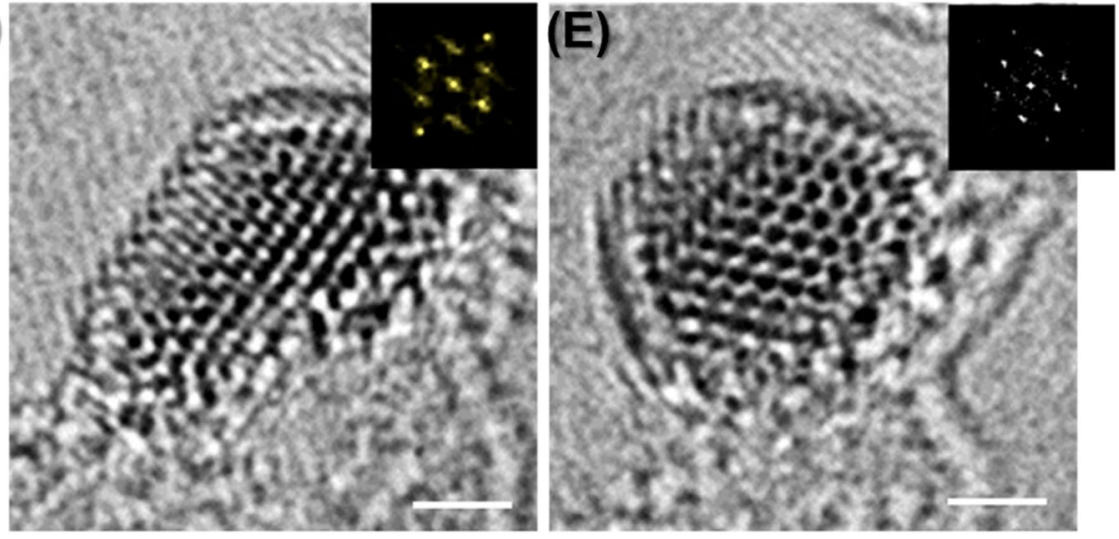

Fig. 1 Atomic resolution TEM images with respect to Ostwald ripening in $\mathrm{Cu}_{x} \mathrm{O}$ NPs on graphene. All scale bars are $1 \mathrm{~nm}$. $\mathbf{a}$, b Crystallization in $\mathrm{Cu}_{x} \mathrm{O}$ NPs from the amorphous phase during electron beam irradiation. The gap of acquisition time between $\mathbf{a}$ to $\mathbf{b}$ is about $6 \mathrm{~s}$. $\mathbf{b}$-d Ostwald ripening process between two $\mathrm{Cu}_{x} \mathrm{O}$ NPs taken by $0.2 \mathrm{~s}$ time-series acquisition. e Crystallized $\mathrm{Cu}_{x} \mathrm{O} N P$ with hexagonal lattice structures $10 \mathrm{~s}$ after taking $\mathbf{d}$

Received: 25 November 2019 Accepted: 3 December 2019

Published online: 16 December 2019

\section{References}

D.C. Bell, C.J. Russo, G. Benner, sub-angstrom low-voltage performance of a monochromated, aberration-corrected transmission electron microscope. Microsc. Microanal. 16, 386 (2010). https://doi.org/10.1017/ S1431927610093670

C.L. Kuo, K.C. Hwang, Does morphology of a metal nanoparticle play a role in Ostwald ripening processes? Chem. Mater. 25, 365 (2013). https://doi.org/10. $1021 / \mathrm{cm} 3031279$

G. Lupina, J. Kitzmann, I. Costina, M. Lukosius, C. Wenger, A. Wolff, S. Vaziri, M. Östling, I. Pasternak, A. Krajewska, W. Strupinski, S. Kataria, A. Gahoi, M.C. Lemme, G. Ruhl, G. Zoth, O. Luxenhofer, W. Mehr, Residual metallic contamination of transferred chemical vapor deposited Graphene. ACS Nano 9(4776) (2015). https://doi.org/10.1021/acsnano.5b01261

R. Ouyang, J.-X. Liu, W.-X. Li, Atomistic theory of Ostwald ripening and disintegration of supported metal particles under reaction conditions. J. Am. Chem. Soc. 135(1760) (2013). https://doi.org/10.1021/ja3087054

P.W. Voorhees, The theory of Ostwald ripening. J. Stat. Phys. 38(231) (1985). https://doi.org/10.1007/BF01017860

\section{Publisher's Note}

Springer Nature remains neutral with regard to jurisdictional claims in published maps and institutional affiliations.

\section{Submit your manuscript to a SpringerOpen ${ }^{\circ}$ journal and benefit from:}

- Convenient online submission

- Rigorous peer review

- Open access: articles freely available online

- High visibility within the field

- Retaining the copyright to your article

Submit your next manuscript at $\boldsymbol{\sim}$ springeropen.com 